\title{
ESTANDARIZACIÓN DEL PROTOCOLO DE DESINFECCIÓN DE DISCO DE HOJA EN LA INDUCCIÓN DE CALLOGÉNESIS DE CORDIA ALLIODORA (RUIZ \& PAV.) OKÉN (LAMIALES: BORAGINACEAE) EN CONDICIONES IN VITRO
}

\author{
STANDARDIZATION OF A PROTOCOL FOR DISINFECTION OF LEAF DISCS IN THE INDUCTION OF \\ CALLUS FORMATION OF Cordia alliodora (RUIZ \& PAV.) OKEN (LAMIALES: BORAGINACEAE) IN VITRO
}

\author{
Rodolfo López Franco ${ }^{1}$, Cesar Iván Murcia Rincón' \\ Paola Andrea López Mora', Jenny Carolina Valencia Rincón ${ }^{2}$ \\ ${ }^{1}$ Laboratorio de Biotecnología adscrito al CIBUQ. Universidad del Quindío. Armenia, Colombia. \\ ${ }^{2}$ Estudiantes de Biología. Facultad de Ciencias Básicas. Universidad del Quindío.
}

Fecha de recibido: Febrero 3 de 2010

Fecha de aceptado: Junio 9 de 2010

Correspondencia: Programa de Biología Universidad del Quindío Av. Bolívar calle 12 norte Armenia Quindío. Correo electrónico: rlopez@uniquindio.edu.co

\section{RESUMEN}

Cordia alliodora (Ruiz \& Pav.) Okén, es una especie con un doble propósito, la explotación comercial y la posibilidad de mejorar el medio ambiente debido a su aporte de nutrientes y a su vinculación con sistemas silvopastoriles. La aplicación de técnicas de micropropagación en especies forestales ha constituido una alternativa útil para aumentar el establecimiento de plantaciones. No obstante, la desinfección de explantes en este tipo de especies ha sido una de las limitantes para el establecimiento in vitro, debido a la presencia de contaminantes que afectan el desempeño de estos bajo estas condiciones; haciendo indispensable el uso de protocolos de desinfección que permitan la disminución en la aparición de agentes contaminantes. El objetivo de la presente investigación consistió en evaluar diferentes protocolos de desinfección de explantes (disco de hoja), para determinar la eficiencia en el menor grado de contaminación sin comprometer su viabilidad. Se evaluaron tres protocolos: 1) López 2) Marulanda et al. y 3) Ramírez - Villalobos et al., aunque los protocolos 2 y 3 presentaron un comportamiento similar estadísticamente se eligió este último ya que fue el que menos comprometió la viabilidad del explante.

Palabras claves: Cordia alliodora, Disco de hoja, protocolos de desinfección.

\section{ABSTRACT}

Cordia alliodora (Ruiz \& Pav.) Oken, is a species with a dual purpose: commercial exploitation and the possibility of improving the environment because of its nutrients and its links with silvopastoral systems. The application of micropropagation techniques in forest species has been a useful alternative to increase the establishment of plantations. However, the disinfection of explants in these kind of species has been one of the limiting factors for establishment in vitro, due to the presence of pollutants that affect the performance of these species under in vitro conditions; making it necessary the use of disinfection protocols that allow the decrease in the appearance of pollutants. The objective of this research was to evaluate different protocols for disinfection of explants (leaf disc), to determine the efficiency in the smallest degree of contamination without compromising their viability. We evaluated three protocols: 1) López 2) Marulanda et al. y 3) Ramírez-Villalobos et al. although protocols 2 and 3 showed similar results statistically, the last one was chosen because it was the one that compromised the least the viability of the explant.

Key Words: Cordia alliodora, leaf disc, disinfection protocols.

\section{INTRODUCCIÓN}

Cordia alliodora (Ruiz \& Pav.) Okén, conocida en la zona cafetera colombiana como nogal cafetero, es una planta magnoliopsida de la familia Boraginaceae cuyo porte puede alcanzar una altura de hasta $30 \mathrm{~m}$, con un diámetro a la altura del pecho de hasta $100 \mathrm{~cm}$; es originaria de América tropical, cuya distribución natural abarca una gran variedad de climas, suelos y topografía, estando presente desde México hasta el sur de Suramérica (1).
Esta especie es característica del bosque secundario y se establece rápidamente en terrenos abiertos (2); posee madera de alta calidad para ebanistería, siendo una árbol de los de mayor valor económico en la región (3), por lo que los agricultores pueden obtener ingresos económicos, cuando se siembra como sombrío en cultivos de café (Coffea sp.) o cacao (Theobroma sp.) (4).

Adicionalmente, algunas situaciones actuales como las restricciones impuestas por las autoridades a la explotación de madera proveniente de bosques naturales, el incremento 
en la demanda de madera en el mercado internacional, o los incentivos ambientales y económicos por captura de dióxido de carbono, han convertido los cultivos forestales en una de las actividades agrícolas con mayor futuro económico (5). Por su porte y envergadura, además de su crecimiento en diferentes condiciones ecológicas, en la región cafetera colombiana se buscan alternativas para su propagación, que fortalezcan programas de reforestación para la recuperación de coberturas vegetales con especies nativas (6).

Las técnicas de cultivo in vitro han desarrollado una exitosa y rápida propagación asexual de un gran número de especies vegetales; la propagación clonal por cultivo de tejidos, viene siendo utilizada para regenerar poblaciones de plantas con características similares, convirtiéndose en una herramienta útil para la conservación y propagación rápida de especies vegetales (7).

Sin embargo, en los procesos de micropropagación vegetal, la presencia de microorganismos contaminantes tanto externos como endógenos, afectan el desempeño de los explantes una vez inoculados en condiciones in vitro, haciendo indispensable el uso de técnicas que permitan la eliminación de dichos contaminantes (8-12).

La desinfección de explantes aislados de plantas leñosas perennes, ha sido siempre una de las limitantes más severas para el establecimiento in vitro de este tipo de especies, reportándose contaminaciones superiores a $90 \%$, como en explantes de guayaba dulce (Psidium guajaba - Mirtaceae) (13); caoba (Swietenia macrophylla King), cedro (Cedrela odorata) (14); Quillay (Quillaja saponaria Mol) (15); y roble (Tabebuia rosea Bertol DC) (5).

Por tanto, el objetivo de la presente investigación consistió en identificar el protocolo de desinfección más adecuado, en la inducción de callogénesis a partir de disco de hoja de Cordia alliodora, para determinar su eficiencia en la descontaminación de los explantes, sin comprometer su viabilidad.

\section{MATERIALES Y MÉTODOS}

\section{Colecta de material vegetal}

Las laminas foliares se colectaron de individuos adultos y juveniles de Cordia alliodora, presentes en el campus de la Universidad del Quindío, ubicado en la ciudad de Armenia en el departamento del Quindío. A la hora de la colecta del material, se tuvo en cuenta que el tejido estuviese fisiológicamente joven y en buen estado (sin rastros de daño mecánico) realizando podas sucesivas, garantizando una entrega inmediata en el laboratorio, a donde se llevaron en recipientes esterilizados.

\section{Fase de laboratorio}

El presente estudio fue realizado en el Laboratorio de Biotecnología Vegetal de la Universidad del Quindío, adscrito al Centro de Estudios e Investigaciones en Biodiversidad y Biotecnología-CIBUQ.

\section{Preparación del medio de cultivo}

Para la preparación del medio de cultivo se utilizaron las concentraciones y cantidades sugeridas por Murashige \& Skoog (MS) (1962) (16); consecutivamente a esta solución se agregaron 30 gramos de glucosa como fuente de carbono; se ajusto el $\mathrm{pH}$ a 5.7-5.8 agregando $\mathrm{KOH}$ al $1 \mathrm{~N}$; igualmente se añadieron $2.8 \mathrm{~g} / \mathrm{L}$ de gelificante (Culturegel) en agitación constante; inmediatamente se sirvieron $20 \mathrm{ml}$ de la solución en recipientes de vidrio debidamente rotulados, según los tratamientos, para luego ser llevados a procesos de esterilización en autoclave durante 20 minutos, a $121^{\circ} \mathrm{C}$ y 15 libras de presión.

\section{Desinfección del material vegetal}

Se trabajaron tres protocolos de desinfección utilizados en algunas especies vegetales. Para todos los protocolos aplicados, se utilizaron hojas en estado juvenil

\section{Protocolo de desinfección según López (2007)}

Las hojas se lavaron con detergente comercial y abundante agua de grifo; luego con la ayuda de un bisturí, se seccionaron los discos de hoja de aproximadamente $1 \mathrm{~cm}^{2}$; posteriormente fueron lavados con agua destilada; consecutivamente, los explantes fueron puestos en una solución al $2 \%$ (0.5 $\mathrm{ml} / 100 \mathrm{ml}$ de agua) del fungicidabactericida comercial KASUMIN durante $20 \mathrm{~min}$. Luego fueron llevados a la cabina de flujo laminar donde se sometieron a lavados con $\mathrm{NaClO}$ al $2 \%$, por dos tiempos diferentes de exposición: 5 y 10 minutos; posteriormente se realizaron tres enjuagues con agua destilada estéril, para ser inoculados en los recipientes que contenían el medio de cultivo.

\section{Protocolo de desinfección según Marulanda e Isaza (2004)}

El presente protocolo sugirió realizar una pre desinfección donde los explantes se lavaron con $200 \mathrm{ml}$ de agua de grifo más jabón detergente de uso comercial y $100 \mathrm{ml}$ de $\mathrm{NaClO}$ al $1 \%$, por $10 \mathrm{~min}$; posteriormente se realizó un lavado con abúndate agua del grifo hasta que desapareciera cualquier residuo visible del detergente utilizado. A continuación los explantes fueron llevados a la cabina de flujo laminar donde fueron puestos en alcohol al $70 \%$ durante un minuto; luego se realizaron tres enjuagues con agua destilada y se dejaron 15 min en una solución de $\mathrm{NaClO}$ al 3\%; se hicieron tres enjuagues con agua destilada estéril y se sometieron nuevamente los explantes durante 5 min en una solución $\mathrm{NaClO}$ al 1\%; a continuación se hicieron tres enjuagues con agua destilada estéril. Adicionalmente, al protocolo anterior se le realizó una modificación, dando como resultado un cuarto tratamiento, donde sometieron los explantes en la segunda solución de $\mathrm{NaClO}$ a mayor tiempo de exposición, durante $10 \mathrm{~min}$, para posteriormente ser inoculados en el medio de cultivo.

3. Protocolo de desinfección según Ramírez et al. (2002). Los explantes fueron tratados con las dosis de $0.5,1$ y $2 \%$ de $\mathrm{NaClO}$ (Cloro comercial: hipoclorito de sodio al 5,25\%), tomando cada dosis en tratamientos diferentes, a dos tiempos de exposición: 5 y 10 min. Posteriormente, se realizaron tres enjuagues con agua destilada estéril, y se llevaron a medio de cultivo. 


\section{Fase estadística}

Para el tratamiento estadístico de los datos se utilizó el paquete estadístico software Statistica 7 (statsoft Inc. 1984 - 2004) bajo Windows. Para la elección del mejor protocolo de desinfección se realizó un análisis de varianza, con un valor de significancia igual $5 \%(\alpha=0.05)$, teniendo como variables numero de protocolo de desinfección, tiempo en solución de $\mathrm{NaClO}$, e interacción entre las dos variables. A los tratamientos que mostraron diferencias significativas, se les realizó la prueba de Tukey la cual se utilizó para tomar la decisión estadísticamente significativa del protocolo de desinfección más adecuado para C. alliodora. Adicionalmente por medio de estadística descriptiva, se determinó el porcentaje de contaminación para cada siembra realizada, con los diferentes protocolos, así como con las diferentes secciones de la lámina foliar utilizadas.

El diseño experimental que se empleó fue el siguiente:

Variable respuesta: Contaminación
Unidad de respuesta: Explante (disco de hoja)

Unidad de muestreo: Cada repetición (30 repeticiones)

Factor de diseño: Desinfección (Concentración de $\mathrm{NaOCl}$ según cada protocolo)

Nivel del factor de diseño:

-5 min

$-10 \mathrm{~min}$

Factor de diseño: Tipo de Protocolo

Nivel del factor de diseño:

-Protocolo 1

-Protocolo 2

-Protocolo 3RESULTADOSY DISCUSIÓN

Se sembraron sesenta explantes por cada protocolo (Tabla 1) y se determinaron los porcentajes de contaminación por hongos y bacterias. El mayor porcentaje de contaminación se registró en el protocolo 1 con un 100\% seguido del protocolo 3 con una contaminación máxima del 26\%; el protocolo 2 determinó una contaminación inferior al $16 \%$.

Tabla1. Resultados de contaminación de disco de hoja, para cada tratamiento, en diferentes concentraciones y tiempos de exposición a NaClO.

\begin{tabular}{|c|c|c|c|c|c|c|}
\hline $\begin{array}{l}\text { \# de explantes } \\
\text { sembrados }\end{array}$ & $\begin{array}{l}\text { Protocolo de } \\
\text { desinfección }\end{array}$ & $\begin{array}{l}\text { Tiempo de } \\
\text { exposición al } \\
\text { Nacío }\end{array}$ & $\begin{array}{c}\text { \# de explantes } \\
\text { contaminados por } \\
\text { bacteria }\end{array}$ & $\begin{array}{c}\text { \# de explantes } \\
\text { contaminados } \\
\text { por hongo }\end{array}$ & $\begin{array}{l}\text { \# de explantes libres } \\
\text { de contaminación }\end{array}$ & $\begin{array}{c}\% \text { de } \\
\text { contaminación }\end{array}$ \\
\hline 30 & 1 & $5^{\prime}$ & 4 & 26 & 0 & $100 \%$ \\
\hline 30 & 1 & $10^{\prime}$ & 5 & 25 & 0 & $100 \%$ \\
\hline 30 & 2 & $5^{\prime}$ & 0 & 5 & 25 & $16 \%$ \\
\hline 30 & 2 & $10^{\prime}$ & 0 & 3 & 27 & $10 \%$ \\
\hline 30 & 3 & $5^{\prime}$ & 0 & 8 & 22 & $26 \%$ \\
\hline 30 & 3 & $10^{\prime}$ & 0 & 6 & 24 & $20 \%$ \\
\hline
\end{tabular}

Según el análisis estadístico, realizado para las pruebas de desinfección de explantes en cada protocolo aplicado, los datos de contaminación mostraron una distribución normal; por tanto se realizó un análisis de varianza para la contaminación por hongos y bacterias (Figura 1).
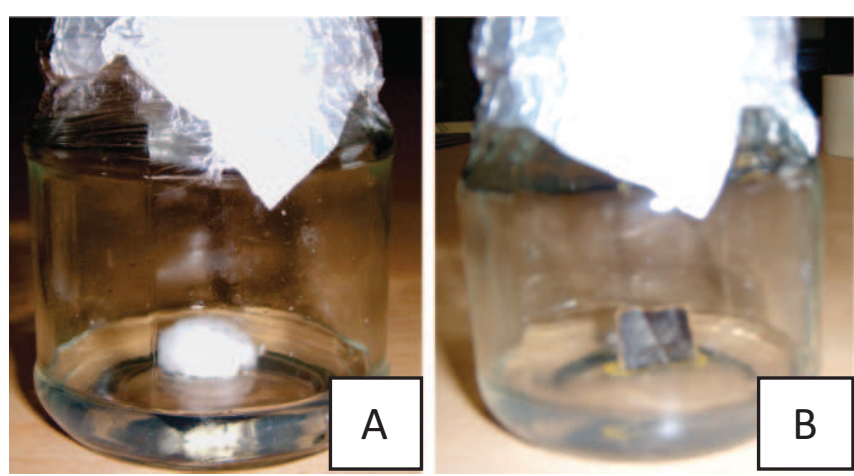

Figura 1. Contaminación de explantes. a). Hongos. b) Bacterias.
En el primer protocolo no se encontraron diferencias significativas entre los tiempos de exposición a $\mathrm{NaClO}$ $(F=0.96, P=0.3)$, mientras que entre los protocolos de desinfección si se observaron diferencias significativas ( $F=62.5, P=0.00)$; por consiguiente para la elección del mejor protocolo de desinfección de explantes de C. alliodora se aplicó la prueba de Tukey, la cual mostró que los protocolos 2 y 3 presentaron el mismo comportamiento estadístico, mientras que el protocolo 1 presentó diferencia con alta significancia (Tabla 3).

Tabla 2. Análisis de varianza Protocolo y tiempo en $\mathrm{NaClO}$ vs. Contaminados por hongo. $\alpha=0,05$.

\begin{tabular}{llll}
\hline & $\mathrm{GL}$ & $\mathrm{F}$ & $\mathrm{P}$ \\
\hline Protocolo & 2 & 62.4 & 0.0 \\
Tiempo en NaClO & 1 & 0.96 & 0.3 \\
Protocolo * tiempo NaClO & 2 & 0.03 & 0.9 \\
\hline
\end{tabular}


Tabla 3. Prueba de Tukey para elección de protocolo según la contaminación por hongo.

\begin{tabular}{lccc}
\hline Protocolo & $\begin{array}{c}\text { Contaminación } \\
\text { media de hongo }\end{array}$ & 1 & 2 \\
\hline 2 & 0.13 & $* * * *$ & \\
3 & 0.23 & $* * * *$ & \\
1 & 0.85 & & $* * * *$ \\
\hline
\end{tabular}

En el caso de la contaminación por bacterias, los resultados del análisis de varianza (Tabla 4) fueron similares a los mostrados por la contaminación por hongos, dado que no hubo diferencias en los tiempos de exposición al $\mathrm{NaClO}$ ( $\mathrm{F}=$ $0.12, \quad P=0.72$ ); sin embargo, entre protocolos si se observaron diferencias significativas ( $F=10.25, P=0.00)$, por lo que fue útil realizar la prueba de Tukey (Tabla 5), la cual mostró que los protocolos 2 y 3 tuvieron comportamientos relacionados, presentándose diferencias altamente significativas entre el protocolo 1 y el protocolo 3.

Tabla 4. Análisis de varianza Protocolo y tiempo en $\mathrm{NaClO}$ vs Contaminados por bacteria $\alpha=0,05$.

\begin{tabular}{llcc}
\hline & $\mathrm{GL}$ & $\mathrm{F}$ & $\mathrm{P}$ \\
\hline Protocolo & 2 & 10.2 & 0.00 \\
Tiempo en NaClO & 1 & 0.12 & 0.72 \\
Protocolo * tiempo NaClO & 2 & 0.12 & 0.88 \\
\hline
\end{tabular}

Tabla 5. Prueba de Tukey para elección del protocolo según la contaminación por bacteria.

\begin{tabular}{cccc}
\hline Protocolo & $\begin{array}{c}\text { Contaminación } \\
\text { media de bacteria }\end{array}$ & 1 & 2 \\
\hline 2 & 0.00 & $* * * *$ & \\
3 & 0.00 & $* * * *$ & \\
1 & 0.29 & & $* * * *$ \\
\hline
\end{tabular}

Al comparar los porcentajes de contaminación, se observó que los protocolos 2 y 3 presentaron porcentajes bajos de contaminación, lo cual puso de manifiesto que la desinfección superficial del material vegetal con soluciones de $\mathrm{NaClO}$, resultó efectiva para controlar los microorganismos contaminantes $(17,18)$.

Aunque es posible utilizar desinfectantes más efectivos como el bicloruro de mercurio $(\mathrm{HgCl} 2)$, no es conveniente debido a que es tóxico y altamente contaminante (11), por lo que varios autores recomiendan el uso del $\mathrm{NaClO}$ como desinfectante en la micropropagación vegetal $(19,20)$.

Para complementar la elección del protocolo, de manera cualitativa, se determino la viabilidad de los explantes después de la aplicación del protocolo de desinfección; se pudo comprobar que el protocolo de Marulanda et al. (2004) (20), fue el que registró menor porcentaje de contaminación, pero a la vez fue el que presentó menor viabilidad de los explantes, ya que se produjo una rápida necrosis en el tejido de aquellos discos de hoja no contaminados; situación acorde con los reportado por Pedroza et al. (2007) (21), quien advierte que aumentos en las concentraciones de $\mathrm{NaClO}$ altera las condiciones fisiológicas de los explantes, generando la necrosis y la muerte de los tejidos cultivados.

Por tanto, podemos determinar que el protocolo tres, propuesto por Ramírez et al. (2002) (19), fue el método de desinfección más eficaz para la desinfección de explantes, en concentraciones de $\mathrm{NaClO}$ al 1,0\%, por $10 \mathrm{~min}$ de exposición; como estadísticamente se comportó de manera similar con el protocolo propuesto por Marulanda e Isaza (2004) (20), adicionalmente permitió que el explante no sufriera necrosis, y por tanto fuese viable para la inducción de callogénesis (no se muestran datos).

No obstante Mroginski \& Roca (1991) (22), señalan que es difícil lograr cultivos completamente estériles para cualquier especie, al igual que Digonzelli et al. (2001) (18), quienes afirman que en diferentes estudios, los explantes que han sido tomados de plantas cultivadas en el campo en climas tropicales son más difíciles y a veces imposibles de esterilizar.

Teniendo en cuenta los resultados estadísticos del ANDEVA, porcentaje de contaminación y calificación cualitativa de la viabilidad de los explantes, se determinó que el protocolo de Ramírez et al. (2002) (19), fue el método de desinfección más idóneo para la fase de desinfección de los explantes, en concentraciones de $\mathrm{NaClO}$ al 1,0\%, durante 10' de exposición, aunque no fue el que arrojó los porcentajes más bajos, las diferencias que existen no son significativas con respecto al protocolo propuesto por Marulanda e Isaza (2004) (20), ya que estadísticamente se comportaron de manera similar; adicionalmente el protocolo 3 permitió que el explante no sufriera necrosis y por lo tanto fuese viable.

De acuerdo con Jiménez et al. (2004) (23), es importante tener en cuenta, la zona del tejido que se utiliza para iniciar el cultivo in vitro, ya que tiene gran influencia en la eficiencia de la desinfección. Los explantes tomados de plantas en crecimiento son más fáciles de desinfectar que los explantes de plantas adultas, donde la desinfección se hace muy difícil (8).

Por lo tanto en la presente investigación se determino de manera cualitativa que el tejido optimo para la especie, son la hojas de arboles juveniles.

En el trabajo realizado por Gutiérrez (2002) (24), en la especie Alnus acuminata a partir de segmentos nodales y hoja, se empleó un protocolo de desinfección con 
concentraciones muy similares de $\mathrm{NaClO}$ y tiempos de exposición a los propuestos en el protocolo de Marulanda e Isaza (2004) (20) y Ramírez et al. (2002) (19). Los resultados indicaron que el tratamiento de desinfección con $1 \%$ de $\mathrm{NaClO}$ produjo menor oxidación en las hojas que en los segmentos nodales (62\% menos). La supervivencia fue también mayor en las hojas, con una diferencia frente a los segmentos nodales del $58 \%$.

Sin embargo, ante los resultados anteriores, se eligió el tratamiento con $1 \%$ de $\mathrm{NaClO}$ y 10 minutos de exposición, tanto para hoja como para segmento nodal, en la medida que presentó menores niveles de oxidación y permitió mayor supervivencia de los explantes, coincidiendo con los resultados obtenidos para C. alliodora en esta investigación. Los análisis estadísticos aplicados en otros trabajos permitieron afirmar que la eficiencia del proceso en cuanto a la desinfección y establecimiento in vitro en esta especie, además puede verse afectada por factores como procedencia del material vegetal, contaminación por microorganismos endófitos, número de ciclos de propagación y por la interacción entre éstos (25).

\section{CONCLUSIONES}

La desinfección de disco de hoja determinó menores índices de contaminación, pero mayor deterioro del explante, cuando se utilizó el protocolo propuesto por Marulanda e Isaza (2004) (20).

El protocolo propuesto por Ramírez et al. (2002) (19), para la desinfección de explantes adultos de annona muricata L., si bien no mostró los índices más bajos de contaminación, sí evidenció la forma más eficiente, en la medida que permitió el establecimiento y sobrevivencia de los explantes de C. alliodora.

La utilización del producto comercial Kasumin (fungicidabactericida de origen biológico) en procesos de predesinfección del disco de hoja de $\mathrm{C}$. alliodora, propuesto por López (2007) (12), no aportó condiciones adicionales de desinfección para los explantes.

\section{AGRADECIMIENTOS}

Los autores agradecen al Laboratorio de Biotecnología Vegetal de la Universidad del Quindío, adscrito al Centro de Estudios e Investigaciones de Biodiversidad y Biotecnología CIBUQ. Así mismo expresan un especial reconocimiento a la Bióloga Lina María Londoño Giraldo quien ha nutrido con sus aportes el desarrollo del presente trabajo.

\section{BIBLIOGRAFÍA}

1. Liegel LH; Stead JW. Cordia alliodora (Ruiz \& Pav.) Okén. Laurel, capá prieto. En: Burns, Russell M.; Honkala, Barbara H., eds. Silvics of North America: 2. Hardwoods. Agric. Handb. 654. Washington, DC: U.S. Department of Agriculture, Forest Service. 1990; 270-277.

2. Marinero, MR. Influencia del Melinis minutiflora Beauv. en el crecimiento de Cordia alliodora (Ruiz y Pavón) Cham. Tesis Mag. Sc. Turrialba, Costa Rica, IICA. 1962; 56.

3. Cordero J; Mesén F; Montero M; Stewart J; Boshier D; Chamberlain J; Pennington T; Hands M; Hughes C; Defletsen G. Descripciones de especies de árboles nativos de América Central. En Árboles de Centroamérica: un manual para extensionistas. Eds. Cordero, J; Boshier DH. OFI-CATIE, Turrialba, Costa Rica. 2003; 473-476.

4. Albertin A.; Nair PK. Farmers Perspectives on the role of shade Trees in Coffee Productions Systems: An assessment from the Nicoya Peninsula, Costa Rica. Human Ecology. 2004; 32(4): 443-463.

5. Suárez I; Jarma A; Ávila M. Desarrollo De Un Protocolo Para Propagacion in vitro De Roble (Tabebuia Rosea Bertol Dc). Rev. Temas Agrarios. 2006; 11(2): 52-62.

6. WAFLA. Gestión Integrada de Recursos Hídricos y Agroforestería en Zonas Áridas, Semiáridas y Sub Húmedas Secas de América Latina. Especies objetivo para sistemas agroforestales en zonas secas de América Latina. 2006; 1.

7. Carrizosa MS; Serrano C. Sistemas modelo para la micropropagación y conservación de especies forestales. En: Memorias de IV Congreso La investigación en la Universidad Javeriana". Bogotá D. C.: Pontificia Universidad Javeriana, 1996; 261272.

8. Pérez P; Jiménez, GE. Micropropagación y fundamentos teóricos prácticos del cultivo in vitro". Conferencias en Biotecnología Agrícola. 1995; 1-10.

9. Leifert C; Cassells A. Microbial hazards in plant tissues and cellculture. In Vitro Cell and Developmental Biology-Plant. 2001; 367:133-138.

10. Suárez A; Compagnone R; Salazar M; Tillett S; Monache F; Di Giulio C; Bruges G. Antinociceptive and anti-inflammatory effects of Croton malambo bark aqueous extract. Journal of Ethnopharmacology. 2003; 88 (1): 11-14.

11. Jiménez V; Castillo J; Tavares E; Guevara E; Montiel M. In vitro propagation of the neotropical giant bamboo, Guadua angustifolia Kunth, through axillary shoot proliferation. Plant Cell, Tissue and Organ Culture. 2006; 86:389-395.

12. López R. Micropropagación in vitro de Guadua angustifolia Kunth, en medio sólido y por inmersión temporal, y estudio de la aclimatación en campo. Tesis Mag. Sc. Biología Vegetal. Universidad del Quindío, Universidad Tecnológica de Pereira, Universidad de Caldas. 2007.

13. Viloria Z. Cultivo in vitro de nudos de guayaba (Psidium guajaba L.). Universidad del Zulia, Maracaibo. 1993; 35. 
14. Abdelnour E.; Muñoz, A. Micropropagación de especies forestales. X Congreso Forestal Nacional de Especies Forestales. San José de Costa Rica. 1997.

15. Prehn D., Serrano C., Berrios CG. y Arce, P. Micropropagación de Quillaja saponaria Mol. a partir de semillas. Bosque. $2003 ; 24(2): 3-12$.

16. Murashige TF; Skoog. A revised medium for rapid growth and bioassays with tobacco tissue culture. Physiology plant. $1962 ; 13: 473-479$.

17. Ramírez M. Tratamientos a plantas madres y al explante para el establecimiento in vitro del guayabo (Psidium guajava L.)". Trabajo de Grado. Maracaibo: La Universidad del Zulia. Facultad de Agronomía. División de Estudios para Graduados. Programa de Fruticultura. 1998; 132.

18. Digonzelli P; Díaz L; Carrizo S; Lafite J; Sosa S. Diferentes dosis de PPM para controlar la contaminación bacteriana y sus efectos sobre el crecimiento in vitro de la caña de azúcar en la etapa de multiplicación. Facultad de Agronomía y Zootecnia. Universidad de Tucumán. Argentina. 2001.

19. Ramírez M; Urdaneta A; León de Sierralta S. Establecimiento in vitro de explantes adultos del guanábano (Annona muricata L.) tratados con hipoclorito de sodio. Rev. Fac. Agron. (LUZ). 2002; 19: 48-55.

20. Marulanda ML; Isaza LV. Establecimiento in vitro de heliconias con fines de producción masiva. Scientia et Technica. 2004; 26: 193-197.

21. Pedroza, J.A., González, S.R. y Téllez, D.C. Micropropagación de Dodonea viscosa (L) Jacq: una especie en vías de extinción. Rev. Colomb. Biotecnol. 2007; 9 (2): 33-44.

22. Mroginski, LA; Roca WM. Establecimiento de cultivo de tejidos vegetales in vitro. In: W.M. Roca y L.A., Mroginski (EDS). Cultivo de tejidos en la agricultura: fundamentos y aplicaciones. CIAT. Cali, Colombia. 1991; 19-40.

23. Jiménez VM; Castillo J; Tavares E; Guevara E; Montiel M. Micropropagación de Guadua angustifolia Kunth a partir de explantes nodales. Memorias del Simposio Internacional Guadua. Pereira, Colombia: Universidad Tecnológica de Pereira. 2004.

24. Gutiérrez LG. Embriogénesis somática en Alnus acuminata H.B.K. y estudio de la variación somaclonal mediante marcadores moleculares. Tesis Doctoral. Universidad Politécnica de Valencia. 2002; 300.

25. Schuler I; Orozco, LA. Manejo y Gestión de la Biotecnología Agrícola Apropiada para pequeños Productores: Estudio de caso Colombia. Bogotá, Colombia. 2006.

26. Londoño-Giraldo LM. Estudio de la embriogénesis somática en Cordia alliodora (lamiales: boraginaceae) a partir de embrión cigótico. Trabajo de grado, Universidad del Quindío. Facultad de Ciencias Básicas. Programa de Biologia. 2008.

27. Suárez, I; Schnell R; Kuhn D; Litz R. Micrografting of ASBVdinfected avocado (Persea americana) plants. Plant Cell, Tissue and Organ Culture 2005; 80:179-185. 